these experiments gave very strong indications that some at least of the leakage of electricity from a charged body suspended in a closed vessel is not through the insulating support but by conduction through the air.

An account of experiments with a soap bubble was given by Boys to the Physical Society in 1888, and in December 1889 and January 1890 he delivered the Christmas Lectures before a juvenile audience at the Royal Institution, which formed the basis of his well-known book on soap bubbles referred to at the beginning of this notice. In this subject Boys found ample scope for the exercise of his wonderful ingenuity and manual dexterity.

Notes on photographs of rapidly moving objects and on the oscillating electric spark formed the subject of a communication to the Physical Society in 1890. He gave a popular lecture at the Edinburgh meeting of the British Association in 1893 in which he showed photographs of rifle bullets in flight and the air waves accompanying them. In a note communicated in 1937 to the Royal Society of Edinburgh, of which he had recently been elected an honorary fellow, he directs attention to the high speed of rotation given to a mirror by very simple means in these early experiments. He had used the rotating mirror to measure times as short as one hundred millionth of a second, and by its aid had found how to get an illuminating spark which lasted for only one thirteenmillionth of a second.

It was in 1888 , in the midst of this wonderfully active period of his scientific life, that Boys was elected a fellow of the Royal Society; he was awarded a Royal Medal in $\mathbf{1 8 9 6}$ and the Rumford Medal in 1924 .

In 1897 Boys became one of the Metropolitan gas referees. He greatly improved the methods of gas calorimetry, and the calorimeter described by him in the Proceedings of the Royal Society in 1903 was adopted as the standard instrument for testing London gas; it came into general use in gas-works throughout Great Britain. He devoted much thought during many years to the planning of a still better gas calorimeter; but it was not until 1934 that he finally arrived at a design which completely satisfied him. This was described in his Guthrie Lecture of that year. Boys tells in this lecture that the idea underlying one important part of the mechanism came to him in a dream. "I was sufficiently impressed by it to get up at six and go to Victoria Street, where I blew in glass the bulb and tube you now see". He was then in his eightieth year.

It is not surprising that Boys, after his experiments with electric spark discharges, should take an interest in the development of a lightning discharge. With the object of investigating this subject, of finding, for example, at what part of its path the discharge begins and the speed with which it extends itself, he constructed in 1900 a moving-lens camera, of which he gave a short description in Nature of November 20 , 1926. Although he was in the habit of carrying this camera about with him, it was not until twenty-eight years after its construction that, while staying with Loomis in America, he succeeded in getting his first photograph which showed the progressive development of a lightning discharge. Boys must have been interested in lightning for at least half a century when this photograph was taken, for in the issue of Nature mentioned above he gives a most interesting account of observations of a distant thunder cloud which he had watched at Wing in 1876 . For every flash seen in the rain cloud or below, and simultaneously with it, one or more very slender flashes of typical lightning (in one case as many as seven) were observed to shoot upwards into the clear sky.

In spite of the handicap of the loss of one eye and very defective vision in the other, Boys continued his varied scientific activities until the end of his long life; when he was eighty he published little books on the natural logarithm and on weeds. It was in this year that he received his knighthood.

Boys does not appear to have been greatly interested in theoretical physics. His delight was in designing, constructing and manipulating apparatus for physical measurements of the highest accuracy, and in overcoming experimental difficulties which to most would have seemed insuperable. He was a really great experimenter, and his methods of working were original and often unconventional. He appears to have been equally original and unconventional in ordinary life.

Boys married in 1892 Marion Amelia, daughter of the late Henry Pollock, and they had one son and one daughter ; the marriage was dissolved eighteen years later.

Boys died on March 30, 1944, in his ninetieth year. C. T. R. WILSON.

\section{Mr. J. A. Gaunt}

News has recently reached Great Britain of the death of Mr. J. A. Gaunt on January 4, 1944 ; he died from myelitis as a prisoner of war in Hong Kong.

Gaunt entered Trinity College, Cambridge, from Rugby as a scholar in 1923, and had a distinguished undergraduate career, obtaining a mark of distinction in the Mathematical Tripos in 1926 and sharing the newly instituted Mayhew Prize. He then started to work on theoretical physics under the late Sir Ralph Fowler and soon became one of the most promising members of the rapidly expanding school which was being established at Cambridge in the latter half of the 1920's.

Gaunt's first paper was on the stopping power of matter for $\alpha$-particles and was completed by March 1927. He next turned to statistical mechanies and extended some work by Fowler and by Eddington on stellar atmospheres. For this work, published under the title "The Debye-Huickel Theory and Stellar Atmospheres" (Mon. Not. Roy. Ast. Soc.), he was awarded a Rayleigh Prize in 1928. He then returned to the more congenial topic of quantum mechanics and wrote a number of short papers in rapid succession on such subjects as the theory of Hartree's self-consistent field and the relativistic theory of an atom with many electrons.

These early papers of Gaunt's were useful contributions to a rapidly growing subject, but his most important work is contained in two long and rather formidable papers published in the Phil. Trans. during 1929 and 1930, the first being on the triplets of helium and the second on continuous absorption.

The problem of calculating the triplet separations in helium was first tackled by Heisenberg, using nonrelativistic quantum mechanics. The calculation is more difficult for helium than for heavier elements, since for helium the usual approximate theory is inadequate, retardation and other relativistic effects being of comparable importance to the spin-orbit and spin-spin interactions. When Dirac's relativistic theory of the electron appeared it was possible to 
extend Heisenberg's work, and Gaunt was first in the field. His work has been superseded by that of others, notably by that of Breit, based upon a more thoroughgoing derivation of the fundamental equations from quantum-electrodynamics, but Gaunt made a very substantial contribution to a difficult problem.

In the 1920's the calculation of the absorption coefficient of matter for radiation was of great importance in astrophysics. Kramers' formula, based upon the old quantum theory and the correspondence principle, was in violent disagreement with the value of the absorption coefficient required according to the current astrophysical theories. It was therefore of considerable importance to calculate what the absorption should be according to wave mechanies. This was first done by Oppenheimer, who obtained a formula substantially different from Kramers'. Gaunt, who was working on the same problem, discovered an important mistake in Oppenheimer's calculations and rehabilitated Kramers' formula. $\mathrm{He}$ also extended Oppenheimer's work considerably.

These two long papers were completed in little more than twelve months work, and show Gaunt's great ability to handle complicated mathematical problems. It is remarkable that Gaunt should have been able to achieve so much in a single year, since he had already determined to give up theoretical physics for what he considered to be more important work. He was elected a research fellow at Trinity in October 1929, but never resided. Instead, he left England and went, under the auspices of the Church Missionary Society, as an assistant master at St. Stephen's College, Hong Kong, where he taught mathematics, English and Scripture to Chinese and
Siamese boys. He acquired a good knowledge of Chinese, and his pupils liked and admired him, but were genuinely perplexed how a man of such ability came to be their teacher.

Gaunt never lost his interest in physics and found time to read such papers as were sent out to him by friends. Music gave him great pleasure, as did the opportunities he had for travel in China, especially in the mountainous regions. When the shadow of war hung over the Colony, Gaunt joined the Volunteer Defence Corps as a gunner, and took part in the brief struggle.

Gaunt was somewhat reserved with most people, but he had a strong sense of humour and a ready sympathy in the everyday affairs of life. It must have cost him much to make the sacrifice of going to China, but it was done with perfect cheerfulness, in obedience to his conviction of the supreme import. ance of Christianity.

A. H. Willon.

WE regret to announce the following deaths:

Prof. R. Bennett Bean, professor of anatomy in the University of Virginia during 1916-41, known for his work on the distribution, development and evolution of man, on September 3, aged seventy.

Lieut.-Colonel J. W. F. Brittlebank, C.M.G., president of the Royal College of Veterinary Surgeons during 1926--28, on December 18, aged sixty-eight.

The Rev. E. Tickner Edwardes, well known for his popular writings on bees and on general natural history, on December 31, aged seventy-nine.

Dr. J. Fitch King, professor of chemistry in Williams College, Williamstown, Massachusetts, on August 29, aged forty-nine.

\section{NEWS and VIEWS}

Prof. A. N. Whitehead, O.M., F.R.S.

THE award of the Order of Merit to Prof. A. N. Whitehead, of Harvard University, announced in the New Year Honours, will be widely acclaimed. Prof. Whitehead was first known as a mathematician, though of an unusual kind. Mathematics for him meant the "development of all types of formal, necessary, deductive reasoning" (preface to "Universal Algebra", 1898). This phase of his career culminated with the publication of "Principia Mathematica" (1910-12). It was afterwards, as most of us thought, that he turned to philosophy-with a remarkable contribution to the theory of knowledge in 1919-20, and later with a complete system of metaphysics expounded in a series of well-known works. It has been pointed out by Prof. V. Lowe (essay in "The Philosophy of A. N. Whitehead", 1941) that there was no sudden change; the philosopher was implicit in the mathematician, as could be seen in a paper of 1905 .

Whitehead's later works have been much read and quoted-often misread and misquoted. That is the fate of a writer who is at times obscure, at times brilliantly epigrammatic. It is characteristic of his attitude to emphasize the need for abstract thought and also the fallacies that arise from it; the need for rule and order in life and also that mere order means futility. Whitehead's essays on the aims of education are too little known. Nobody has argued more persuasively for the value of history in educa- tion. As is more widely known, few have viewed human history with so keen and comprehensive an eye, and so wide and fine a sympathy.

\section{Organization of Science in Great Britain}

Av interim memorandum from the sub-committee on the future scope and organization of science in Great Britain which has been issued by the Parliamentary and Scientific Committee urges as an immediate measure the appointment by the Government of a committee, with the widest powers of securing information, to review the existing position of industrial research and development in British industry, and to plan a programme (covering, say, the next five years) aimed at remedying the most important defects and gaps in that field, so far as the national interest is concerned. Such a review would involve consideration of existing national resources at home, the probable economic position of Britain in the postwar world, and the lines along which the immediate, vigorous and large-scale application of scientific knowledge is likely to yield the most fruitful results. In this connexion the sub-committee stresses the necessity for special attention to scientific research on the treatment of coal. The review would also involve investigation into the points at which British industry in general, and certain industries in particular, have failed in the past to utilize scientific knowledge, the loss to the national interest which has resulted from this failure and the steps which 